\title{
Reformas de la Administración Local durante la Dictadura: de la Junta de Arbitrios a la Junta Municipal (1923-1927)
}

\section{Paulina Morala Martinez}

\section{1.-Introducción}

Este trabajo se ciñe a una época muy concreta, que va entre el 13 de septiembre de 1923, fecha del golpe de Estado de Primo de Rivera, a marzo de 1927, que es cuando la Junta de Arbitrios pasa a constituirse en Junta Municipal.

El elegir este periodo tan concreto viene motivado porque el régimen político, la Dictadura, va a tener una importancia primordial en el desarrollo del proceso, que va a llevar al cambio del organismo municipal.

Ya desde antes existía en Melilla una profunda corriente de opinión que se mostraba favorable a la equiparación administrativa de la ciudad con el resto de España, mediante la implantación del ayuntamiento.

Esta corriente está representada básicamente, por las entidades económicas de la ciudad, y sobre todo por el periodico local El Telegrama del $R f f$, principal fuente de nuestro trabajo, cuyo director Cándido Lobera será el máximo defensor de un ayuntamiento para Melilla y figura clave en este proceso.

Pero es con la llegada al poder de Primo de Rivera, y con su prometida política de reformas, cuando los melillenses creen llegado el momento de conseguir sus peticiones. Sin embargo, esto no ocurrirá así.

Melilla no será alcanzada por la política nacional de reformas en la administración local; que tendrá su culminación en el Estatuto Municipal. Que Melilla sea una excepción viene dado por la peculiaridad de su propia administración, constituida por un organismo especial, la Junta de Arbitrios, en el que los militares tienen un papel preponderante.

Sin embargo, y siguiendo el ejemplo de Ceuta, Melilla pasará a tener una Junta Municipal en 1927.

El papel de los melillenses, con sus peticiones a favor de un ayuntamiento, va a ser muy importante durante todo el período, a través de campañas de prensa y cartas al gobierno, mediatizadas por la censura. 
Melilla experimenta durante los últimos años del siglo XIX y primeros del $\mathrm{XX}$, un gran cambio. La ciudad crece extraordinariamente, y la población civil empieza a cobrar mayor importancia tanto cualitativa como cuantitativamente. Al romperse el cerco de la ciudad y alejarse de ella el frente de batalla, el papel del ejército como director de la vida ciudadana dejó de ser imprescindible. Entonces comienzan a oírse voces pidiendo el cambio del régimen municipal.

En estos intentos de cambio de régimen, encaminado a conseguir un ayuntamiento, hay dos fechas claves, 1918 y 1921 (1).

El 13 de diciembre de 1918 se firmó un Real Decreto por el que se creaba el Ayuntamiento de Melilla. Sin embargo este Real Decreto no fue bien recibido por la población melillense, porque creaba dependencias de Málaga, al encuadrar a Melilla dentro de su provincia. Por otra parte, también existió el temor de que se equiparasen los tributos melillenses a los de la Península. Aunque estas protestas no significaban que se prefiriese continuar con la Junta de Arbitrios, el Decreto nunca se llevó a cabo.

También en esas fechas se ordenó crear un censo electoral, pero este fue también olvidado sin tomarse nunca en cuenta.

En el año 1921, vuelven a recrudecerse los movimientos en favor de un régimen civil. El 21 de junio se dictó un Real Decreto que en su artículo 1.0 señalaba: "Se crea una comisión encargada de proponer al Gobierno el régimen definitivo a que habrá de someterse el Municipio de Melilla, mandado crear por el R. D. de 13 de diciembre de 1918."

Este R. D. despertó bastante eco en la ciudad, de manera que, la Junta de Arbitrios por una parte, y las entidades económicas por otra, redactaron sendos documentos en los que exponian su visión de como debia ser el régimen a que debía someterse el Municipio de Melilla.

La Junta de Arbitrios en sus conclusiones se proclama representante del sentir del pueblo melillense, ya que su propuesta fue leida el 3 de julio de ese año, ante el público en un mitin celebrado en el teatro Kursaal.

Las distintas corporaciones económicas crean la "Comisión Unica de Fuerzas Vivas", presidida por Cándido Lobera, que también elabora sus conclusiones "como representantes del sentir melillense". Estas corporaciones económicas (2) dirigen un escrito al Presidente del Consejo de Ministros, en un periodo inmediatamente anterior al promulgamiento del $R$. D., para pedir que se conceda a Melilla un régimen civil, basado en:

1. Implantación del régimen civil en Melilla desligándola de Málaga en el orden administrativo local.

(1) Pasa la evolución de la administración local antes de estas fechas, véase: Francisco Saro Gandarillas, "Municipalidad y Administración Local, antecedentes a la constitución del Ayuntamiento de Melilla". Melilla, Revista Aldaba, año 2.', número 3, 1984.

(2) Cámara Oficial de Comercio, Industria y Navegación; C. Oficial Agrícola; Asociación de Propietarios y Unión Gremial Mercantil. 
2. Nombramiento de una comisión extraparlamentaria para que se ocupe de un organismo que sustituya a la Junta de Arbitrios.

3. ${ }^{\circ}$ Creación de un organismo superior al municipal, análogo a los Cabildos Canarios.

4. Creación de una secretaria civil a cargo de la autoridad gubernativa de la que haya de depender la administración local.

5. Creación de un distrito electoral en Melilla.

Los partidarios de este régimen acusan al movimiento que se opone a él de ser representantes de la fuerza del caciquismo, que maniobran para que todo continúe igual.

Acusaciones basadas en el hecho de que el Reglamento de la Junta ha sido modificado, ampliando los poderes de los vocales y la duración de su mandato. Asi, mientras permanece el artículo 18, que otorga un poder omnímodo al Presidente (3), otros artículos como el 89 que prohibia la reelección de los vocales civiles en el plazo de dos años ha sido derogado (4), eternizándose las mismas personas en los cargos.

Estas acusaciones, efectuadas por primera vez en estos momentos, serán repetidas muchas veces durante todo este periodo, hasta la constitución de la Junta Municipal.

Los principales portavoces de este descontento son los distintos organismos económicos, y el periódico El Telegrama del Rif. Pero hay también otras opiniones de altos cargos militares y civiles que se muestran favorables al cambio de régimen.

Como ejemplo, valga la opinión del Jefe de Negociado de Marruecos, Carlos' L. Lamela, en un informe elevado al Ministro de la Guerra en 1920 (5):

"Es, a mi juicio, de urgente necesidad que se resuelva la cuestión municipal de Melilla, dando cumplimiento a la Real Orden de 13 de diciembre de 1918, y con ello una satisfacción a la Constitución $\mathrm{y}$ a las leyes.

Desde 1894 la población de Melilla viene solicitando en vano que se organice en dicha ciudad un ayuntamiento constitucional, asunto que fue objeto de debates parlamentarios desde el año 1901, y que alcanzó estado legal con la publicación del Real Decreto que antes se menciona.

Termina el informe con una clara afirmación:

"Yo opino, que por el bien del Ejército, por su esclarecida reputación, y por

el bien de los intereses de la ciudad debía establecerse un ayuntamiento."

El ejército no mostraba oposición a la transformación de la Junta de Arbitrios

(3) Es un precepto que deja al General Jefe la decisión en las mociones que se presentan, siendo facultad suya el consultar o no a la Junta.

(4) Una R O. de 1905 autorizó la reelección de la mitad de los salientes y otra en 1921 creó el cargo de vocal vitalicio.

(5) Ese informe está recogido en el libro del Vizconde de Eza: "Mis responsabilidades en el Desastre de Melilla..." Madrid 1923. El informe está fechado en 1920. 
en ayuntamiento, por lo menos una parte importante de él, ya que asi se verían libre de una importante carga de trabajo. El general Berenguer en un telegrama al Presidente del Consejo de Ministros, Allendesalazar, dice:

"No sólo no existe.la más mínima hostilidad a la implantación del régimen civil en Melilla por parte del ejército de Africa sino que éste ha de verlo con gusto." (6)

\section{3.-El golpe de Estado y la reforma de la Administración Local}

Si durante 1921 hubo un gran movimiento en favor del régimen municipal, éste no se vio en absoluto coronado por el éxito. Se elevaron unas conclusiones al Gobierno, se elaboró un censo electoral, pero no tuvieron ninguna consecuencia práctica, permaneciendo la situación estancada.

Cuando el 13 de septiembre de 1923, Primo de Rivera da el golpe de Estado, es recibido con alegría tanto por la Junta de Arbitrios como por las entidades que se habian mostrado partidarios de un régimen civil. Para éstos la política de reformas que promete Primo de Rivera, y su deseo de acabar con el caciquismo, significan una reactivación de su esperanza de lograr un cambio apetecido.

Por Real Decreto de 4 de octubre de 1923, disuelve los ayuntamientos "semilla y fruto de la política partidista y caciquil" y promete elaborar nuevas leyes para que estos sean gobernados de una manera justa y representativa.

En Melilla estas noticias despiertan grandes esperanzas, de manera que vuelve a tomar gran importancia la corriente de opinión a favor del cambio de régimen municipal. El Telegrama del Rif comienza una campaña de prensa en este sentido (7). En ella se vuelve a recordar el nulo resultado obtenido anteriormente, atribuyendo el fracaso a la presión del caciquismo.

Por ello, el recién creado Directorio Militar, aparece como la solución para acabar con el caciquismo en Melilla e implantar el régimen civil, igualándola a las otras ciudades españolas.

"El Directorio que ha desterrado la influencia y reducido a cenizas, el caciquismo, no debe tolerar que el requisito de Melilla - caciquismo al finsubsista más tiempo." (8)

Por otro lado, simultáneamente, las entidades económicas de Melilla vuelven a dirigirse al Gobierno, esta vez al Directorio. Señalan que al haber acabado el peligro de caciquismo, que era lo que impedía que existiera un régimen general en Meli-

'(6) Esta cita textual es recogida por El Telegrama del Rif en su n. 8.116 de 2 de noviembre de 1923, on un artículo titulado "Reformas en el régimen administrativo de Melilla".

(7) Son una serie de artículos bajo el título "Reformas en el Régimen administrativo de Melilla". El primero de ellos se publica el 18 de octubre de $1923, \mathrm{n}^{\circ} 8103$.

(8) Articulo firmado por LOBERA, C., y publicado el 2 de noviembre de 1923. Cuarto de la serie antes citada. 
lla, es preciso que se incluya a esta en el "mismo régimen que el Directorio prepara para los ayuntamientos de la Peninsula".

Todas estas manifestaciones no encuentran ningún eco en los organismos oficiales ni en el Gobierno. No hay, por tanto, ninguna aclaración de si Melilla va a ser incluida, o no, dentro de la competencia del Estatuto que se está preparando. Prueba de ello es la indeterminación que muestra el Gobierno el 2 de marzo de 1924, cuando en la Junta de Arbitrios es leida una Real Orden que dejaba en suspenso la petición de esta Junta, solicitando el aumento de cuatro vocales civiles y militares, hasta que no se determinase la reorganización administrativa de la Península.

Las esperanzas que esta decisión pudo suscitar, pronto se vieron frustradas al publicarse el Estatuto Municipal.

\section{4.-El Estatuto municipal}

Debido al impacto que causó en la opinión pública melillense, y a la posterior importancia que tendria en el Estatuto que regiria la Junta Municipal de Melilla, es preciso deternerse en su elaboración y contenido.

A finales de septiembre de 1923, Primo de Rivera pidió a diversas personas la redacción de memorias sobre la administración local. Este proyecto finalmente fue encargado a Calvo Sotelo, exsecretario político de A. Maura, al que Primo de Rivera nombró, en diciembre, Director General de Administración local.

Al aceptar el cargo, Calvo Sotelo impuso como condición que pudiese seguir las directrices del proyecto presentado. Por tanto, el Estatuto Municipal, que fue promulgado el 4 de marzo de 1924, refleja el ideario de Calvo Sotelo y el maurismo.

Este Estatuto comienza con la afirmación de que: "El Estado para ser democrático, ha de apoyarse en Municipios libres."

En él se introducen importantes reformas como:

-Afirma la plena personalidad de las entidades municipales, y en consecuencia reconoce su capacidad jurídica integra, en todos los órdenes del derecho y de la vida.

-El Estatuto trata de reconocer las reales diferencias existentes entre las variedades de convivencia comunal, otorgando a cada Municipio "el derecho a dictarse su propia norma de funcionamiento". Es el llamado régimen de Carta.

- Se capacita a las mujeres cabezas de familia para votar y ser elegidas para cargos municipales.

- Se extiende el priıcipio de incompatibilidad a los representantes de gremios relacionados con abastos públicos, a los letrados, y procuradores de litigantes con el Ayuntamiento, etc...

-Amplia las facultades económicas y administrativas de los Municipios.

Se introducen concejales corporativos (1/3 del total). En esto sigue la línea de Maura y Canalejas. Al individualismo que suponia la democracia se opone la 
representación de las entidades naturales que son la familia, el Municipio y las organizaciones culturales y profesionales.

Aunque este Estatuto suponía un gran paso en la reforma del pais, de manera que se ha llegado a decir que fue la única reforma estructural del Directorio militar, no se llevó nunca a la práctica.

Los ayuntamientos continuaron en manos de la pequeña oligarquía local en la que se asentaba el caciquismo rural, la adhesión de los nuevos concejales a las Uniones Patrióticas no significó más que un oportunismo interesado.

Pero, a pesar del relativo fracaso que a la larga significó este intento de reforma, durante los últimos meses del año 23 y primeros del 24 fue esperado con gran expectación y al conocerse despertó grandes esperanzas entre los partidarios de una reforma en la administración local.

\section{5.-El Estatuto municipal y la opinión melillense}

Aunque ya desde que se tuvo noticias del comienzo de la elaboración del Estatuto, habia despertado interés en Melilla, es ahora en el momento inmediatamente anterior a la promulgación del Estatuto, cuando este interés alcanza su punto máximo.

$\mathrm{Si}$ en un principio se tuvieron fundadas esperanzas de que Melilla se viese incluida en la reforma, cada vez se van perdiendo más rápidamente. A pesar de ello, hasta unos dias antes de la puesta en vigor del Estatuto, siguen apareciendo en el periodico artículos en los que se comenta lo que se conoce del Estatuto, señalando que la autonomía que concede es lo más idóneo para Melilla, y que por tanto viene a significar la culminación de los deseos de todos de tener "un régimen especial adecuado". Lo que representa que aún se tenia por cierto que Melilla se veria afectada por el Estatuto (9).

Por ello cuando el primero de abril entra en vigor el Estatuto en todos los municipios españoles, excepto en Melilla, la decepción es palpable. Melilla se siente excluida de algo que esperaba desde hace tiempo, y creía tener cercano. Además el hecho de que hasta los pueblos más pequeños y miserables hayan tenido su reforma, mientras Melilla debe continuar igual, hace que se sientan aislados del resto de España, y además heridos en su orgullo.

Entre las polémicas y opiniones que provocó en Melilla esta exclusión, hay un hecho de máxima significación, tanto por el eco despertado como por haber sido protagonizado por Cándido Lobera, personaje básico en este asunto. El día 16 de mayo de 1924 leyó ante la Junta de Arbitrios una carta. En ella, y tras asegurar que no era su intención ir contra la Junta de Arbitrios, afirma tajantemente que el mandato de la Junta había terminado el 31 de marzo de 1924. Esa afirmación se

(9) El último de ese estilo fue "Melilla y el nuevo Estatuto Municipal" publicado el 27 de marzo . de 1924, en El Telegrama del $R U$. 
fundamenta en el hecho de que el ser Melilla reconocida como un municipio, se ve afectada por las disposiciones del Estatuto, ya que en sus preceptos no se exceptúa a Melilla y en su disposición final se señala:

"A partir de primero de abril próximo, quedan derogadas todas las leyes, reales decretos, reales órdenes, reglamentos, disposiciones que se refieren a la administración municipal, con la única excepción de las que la ley declare vigente."

Cándido Lobera termina su carta señalando, que, por tanto, al haberse acabado el mandato de la Junta legalmente debe constituirse un Ayuntamiento.

La Junta de Arbitrios admitió la carta y fue tratada en la siguiente sesión, el día 19 de mayo.

En ésta el vocal secretario leyó el informe en el que se declaraba que la Junta hubiera podido dejar de admitir la afirmación de Cándido Lobera, ya que éste se amparaba en el R. D. de 29 de octubre de 1923 pero la afirmación no era queja ni reclamación y además tenía carácter político. La afirmación del señor Lobera debe dirigirse a la superioridad que es quien decide (10).

Con este informe la Junta buscaba no pronunciarse sobre el contenido de la carta, sino limitarse a rechazar el procedimiento. Pero varios vocales manifestaron sus dudas de que estuviese en la legalidad la Junta de Arbitrios. Ante esto el Teniente Auditor de $1 .^{\mathrm{a}}$ Manuel Salinas expuso que estaba muy clara la legalidad de la permanencia de la Junta de Arbitrios, por varios razones:

- La Junta de Arbitrios no es un organismo municipal sino una entidad administrativa, subordinada a Guerra. Ya que para existir un organismo municipal tenbrá que existir un ayuntamiento elegido por sufragio universal.

El R. D. de 13 de diciembre de 1918, por el cual se creaba el Ayuntamiento de Melilla no se ha llevado a efecto.

En julio de 1921 se dictó otro que no corrobora con el anterior sino lo deroga completamente al hablar de crear una comisión para proponer al Gobierno el régimen definitivo.

Por último, la cláusula derogatorio se refiere a la administración municipal, pero se emplea el adjetivo municipal en su valor legal, por lo que no se refiere a un organismo que sólo desempeña las funciones municipales. Además esa cláusula derogatoria tiene algo de valor formulario, y no existe ninguna disposición que especificamente deroge el mandato de la Junta de Arbitrios.

En esta pequeña polémica llaman la atención varios puntos. En primer lugar que Cándido Lobera adoptara esa medida extrema de dirigirse directamente a la Junta de Arbitrios, para señalar la extinción de su mandato, y no lo hiciese al Gobierno que era quien podía tomar una decisión al respecto.

En cuanto a la contestación dada por la Junta de Arbitrios hay dos posturas,

(10)El R. D. señala que: "Todos los habitantes en España mayores de edad cualquiera que sea su clase y condición podrán exponer sus quejas y reclamaciones de carácter municipal ante el ayuntamiento que les corresponda." 
por un lado el informe del secretario, que remite a Candido Lobera a la superioridad, sin dar opinión sobre su afirmación.

Por otra, el Teniente auditor hace un rechazo pleno de la afirmación de Cándido Lobera, en varios puntos. Estos puntos son en su mayoria rebatibles, ya que su apoyo no es sólido. del Rif:

Los dos primeros fueron contestados en su momento por El Telegrama

"Siendo la Junta de Arbitrios una simple dependencia de Guerra, sin mandato del pueblo de Melilla ¿qué papel desempeñan en ella los vocales civiles? Si se niega a Melilla la realidad jurídica de su municipio. ¿Qué valor tienen las leyes, decretos y demás disposiciones que aluden a su término municipal en el Juzgado, en el Registro y en el propio Ayuntamiento mandado crear?"

En cuanto al último argumento de que la disposición derogatoria tiene carácter formulario, cae por su propio peso. Pero a aclararlo, y demostrar su verdadero carácter, viene una R.O. de 30 de enero de 1925, que señala en su preámbulo:

"Esta R. O. es dada porque en más de una ocasión se habian dado indebidamente disposiciones contrarias al Estatuto Municipal, llegándose a suponer que sólo están derogadas por éste aquellas leyes, reglamentos y ordenanzas que el mismo Estatuto declara sin vigor, y que por tanto las restantes deben regir todavía.

Semejante interpretación carece en absoluto de fundamento, dada la disposición final del Estatuto en cuyo precepto han de considerarse incluidas todas las leyes vigentes."

Tras este incidente entre la Junta y Cándido Lobera, el periódico dedica varios artículos a la actitud de la Junta en esa sesión que califica de "lamentable". Esto motiva un aumento de la tensión, llegándose en una sesión de la Junta de Arbitrios a acordarse elevar "la más enérgica protesta por la campaña de prensa que se ha hecho sobre este desdichado asunto..."

Simultáneamente a ese acontecimiento, una coalición de las entidades económicas melillenses se entrevista con Calvo Sotelo, en Madrid, para pedirle que venga a Melilla a pronunciar una conferencia sobre el Estatuto Municipal. Calvo Sotelo aceptó la invitación.

Por último el 26 de junio de ese mismo año, la Junta de Arbitrios deja de depender del Ministerio de la Guerra, para pasar a hacerlo de la Oficina de Marruecos.

Es en este momento cuando parece que está más cerca el logro de un ayuntamiento para Melilla. Por un lado, se recrudece la campaña de opinión; por otro, Calvo Sotelo acepta venir a Melilla a hablar sobre el tema, y, por último, que la Junta de Arbitrios pasase a depender de la Oficina de Marruecos, perdiendo su carácter de dependencia del mando del Ministerio de la Guerra, lo que justificaba su carácter militar.

Esa sensación de que pronto va a producirse el cambio perdura hasta el mes de 
julio (11) pero a partir de ese momento se va a producir un cambio muy apreciable en las opiniones y los acontecimientos.

\section{6.-Primo de Rivera y la Junta de Arbitrios.}

Este nuevo periodo se va a caracterizar primero, porque comienzan a escasear en la prensa las opiniones y noticias referentes al posible cambio de régimen, y, segundo, porque comienza a hablarse de reformas en la Junta, ajustándose al Estatuto Municipal pero siempre contando con la permanencia de ésta y de su composición civico-militar.

No es dificil relacionar este cambio radical en las actitudes de los principales defensores de los ayuntamientos, con la visita que Primo de Rivera hace a Melilla, los últimos días del mes de julio del 24.

También, el recrudecimiento de la guerra con Marruecos va a ocupar todo el panorama de la actividad, relegando a un segundo plano los demás temas.

El Telegrama del Rif, en abril de 1925, hace mención por primera, y única vez, de las razones que han motivado el repentino silencio de los que pedian la constitución de un ayuntamiento, y que no es otro que el desagrado mostrado por Primo de Rivera, ante esa actitud. Aunque el artículo, como es lógico, no habla de imposición ni de censura, no es difícil leerlo entre líneas:

"El Presidente del Directorio Militar es un enamorado de la Junta de Arbitrios de Melilla. No es extraño, pues, que rechazara la petición de las entidades económicas (...) de constituir un ayuntamiento, creado por el R.D. de 1918 , y que le parecieran mal los actos de civismo de nuestro director (...) Por tal motivo ha cesado la campaña en favor de un cambio de régimen."

Otra prueba más de la inclinación que sentía Primo de Rivera por la Junta de Arbitrios va a producirse con motivo de la visita de éste a Ceuta. Allí pronunció un discurso donde señaló su admiración por la Junta de Arbitrios de Melilla, "verdadera expresión de la autonomía municipal y verdadero principio de la administración pública", tomando la decisión de sustituir el Ayuntamiento de Ceuta por una Junta de Arbitrios, semejante a la de Melilla.

Paralelamente a esta decisión de Primo de Rivera, que debió acabar con las últimas esperanzas de implantación de un Ayuntamiento, en Melilla empieza a hablarse de plantearse la elaboración de un nuevo reglamento para la Junta de Arbitrios.

Al pasar a depender de la Oficina de Marruecos, y no del Ministerio de la Guerra era necesario variar las funciones y competencias de la Junta. Esas variaciones en el Reglamento son autorizadas por una R. O. de agosto de 1924.

(11) El día 12 de dicho mes El Telegrama del Rí publica un articulo titulado "Nueva fase en la Junta de Arbitrios" donde se lee: "La Junta de Arbitrios entra en una nueva fase, a nuestro juicio breve etapa para implantar el Ayuntamiento." 


\section{7.-Proyecto para un nuevo reglamento}

Este proyecto de nuevo reglamento arranca de una idea del presidente de la Junta, el general Garcia Aldave, que influido por tantas opiniones contrarias al caduco reglamento vigente, pensó adecuar al Estatuto Municipal de marzo del 24 a la Junta de Arbitrios, pero manteniendo su constitución cívico-militar y su proporción actual de votos.

Las líneas generales de este proyecto son conocidas en mayo de 1925, definen una Junta presidida por el General y con 30 vocales, 15 militares (jefes de cuerpos de Melilla) y 15 civiles, elegidos por los distintos gremios.

Los civiles se renovarán cada tres años, no pudiendo volver a ser reelegidos hasta que transcurran tres años, para desterrar la permanencia de los mismos hombres en los mismos puestos.

La comisión permanente ésta formada por el Presidente y cuatro vicepresidentes, dos civiles y dos militares.

Se crean los cargos de pagador y secretario de plantilla. Pero este Reglamento no será nunca puesto en práctica. Al crearse la Junta de Arbitrios de Ceuta era necesario dotarla de un Reglamento adecuado. Al empezarse a elaborar este reglamento, aunque sólo estaba dirigido a Ceuta, en Melilla fue visto como pensado también para ella, por lo que se paralizó esta reforma del Estatuto.

\section{8.-El Reglamento del régimen local de Ceuta}

Este nuevo Reglamento fue redactado entre los años 25 y 26 , por una comisión presidida por Calvo Sotelo y formada por:

Un representante de la Oficina de Marruecos (Saura y, después, Sangroniz); un representante del Ministerio de Guerra (T. col. García Alvarez); un representante de la Junta de Arbitrios de Melilla (P. Sanabra); un representante del Ayuntamiento de Ceuta (J. Matrés).

Como es lógico, en el Reglamento elaborado, tuvo gran influencia el Estatuto Municipal, ya que su creador era ahora Presidente de la Comisión.

El Estatuto para Ceuta fue publicado en "La Gaceta de Madrid" el 27 de octubre de 1926. Está compuesto por dos libros, estando el segundo dedicado a la Hacienda Municipal, por lo que aqui no lo trataré. Es por tanto el primero el que más interés despertó. Aunque el Estatuto es muy extenso, señalaré los puntos más importantes:

- Ceuta estará regida por una Junta Municipal, con la misma capacidad legal que se otorga a los Ayuntamientos.

- Esta Junta se comprondrá de:

- Un Presidente General o Coronel en activo en la población; 11 vocales natos - tres vecinos de la ciudad-; Comandante de Marina; un Jefe de cada una de las armas o cuerpos de la plaza.

Los once vocales serán elegidos por sufragio restringido, se renuevan por mitad 
cada tres años y no pueden ser reelegidos hasta tres años después. Las vacantes serán cubiertas por suplentes.

- Tendrán derecho a votos los vecinos mayores de 23 años. Para poder ser elegido hay que tener más de 25 años, figurar en el censo y saber leer y escribir.

- De entre los tres vocales natos civiles, se elegirán un vicepresidente que sustituye al presidente en caso de ausencia. Además del vicepresidente primero habrá otros cinco vicepresidentes: dos vocales natos y tres electivos.

- La Junta, en pleno, celebrará tres sesiones anuales, quedando completamente prohibido tratar de cuestiones políticas. La Junta publicará un "Boletin Oficial" que podrá ser bisemanal como máximo, y sustituye al "Boletín Oficial de la Provincia".

- Se nombrarán una serie de funcionarios municipales como: secretario, interventor, arquitecto, abogado, médico, farmacéutico, veterinario..., que serán elegidos por concurso. Los empleados administrativos entrarán por oposición.

- Los acuerdos de la Junta referentes al régimen de la Corporación serán recurribles ante el Consejo de Ministros. Este Estatuto de la Junta Municipal de Ceuta, guarda bastante semejanza con el Estatuto Municipal, asi como el proyecto de Reglamento que se estaba elaborando por la Junta de Arbitrios de Melilla.

En la composición es bastante parecida al Reglamento porque mantiene también una composición mixta entre civiles y militares, pero en la Junta Municipal se da mayoría de civiles que son 14 frente a 8 militares, mientras que en el proyecto para Melilla se mantiene la igualdad. Además hay otra diferencia sustancial, en el Reglamento melillense la elección se produce por gremios, mientras que en el Estatuto ceutí es por sufragio restringido.

Las semejanzas con el Estatuto son muchas, ya que la población es definida del mismo modo, así como los derechos y deberes de los vecinos. En materia de empadronamiento también reproduce la normativa dada por el Estatuto Municipal.

Los casos de incompatibilidades para los vocales y los casos en que éstos pueden excusarse, siguen paso por paso al Estatuto Municipal. Igual sucede con los artículos referidos a tratar los particulares de las sesiones, y la de los funcionarios municipales y sus atribuciones.

Por último, se establece que contra cualquier acuerdo de la Junta no cabrá otro recurso que el establecido en el Estatuto.

\section{9.-Proceso para la implantación de la Junta Municipal en Melilla}

Los vecinos de Melilla convencidos, a la fuerza, de la imposibilidad de conseguir un ayuntamiento, y de la continuidad de la Junta de Aribitrios "cual desea el ilustre marqués de Estella", fijan su atención en el proceso de elaboración del Estatuto de Ceuta.

Se tiene la esperanza de que una vez elaborado se aplique también a Melilla con 
lo que ello supondria de positivo. Entre las acciones llevadas a cabo, ante este hecho, destacan el interés mostrado por las Cámaras de Comercio, Propiedad Agricola, Sindicato Minero, y Unión Gremial Mercantil, que bastante meses antes de la promulgación del Estatuto para Ceuta, comienzan a interesarse oficialmente por su contenido y por saber si va afectar a Melilla.

Asi, en diciembre del año 25, se dirigen al Presidente de la Junta de Arbitrios, para pedirle apoyo para las gestiones que están realizando cerca del Gobierno para que "antes de promulgar el nuevo Reglamento por el que ha de regirse la corporación municipal, se haga público, y se pueda informar de él, a dichas entidades". La Junta Municipal se niega a colaborar, alegando su carácter militar.

Esta acción emprendida por las entidades económica tiene dos consecuencias. En primer lugar, el Gobierno contesta a las preguntas de las entidades que el Reglamento está todavía en elaboración y que compete únicamente a Ceuta, lo que hace que en Melilla cunda el temor de volver a ser marginados en la reforma.

Por otra parte la actitud de la Junta de Arbitrios, que no apoya a los demás organismos, por su carácter militar, hace que se redrudezcan las críticas hacía su composición.

Hay otro acontecimiento que va a volver a incidir sobre este hecho. Se implantan en Ceuta y Melilla los mismos tributos que en la Península, lo que motiva grandes protestas de todas las asociaciones económicas de las dos ciudades, pero, mientras que en Ceuta cuentan con el apoyo de su ayuntamiento, en Melilla la Junta de Arbitrios se vuelve a negar.

Los melillenses se lamentan, por tanto, que debido a su estructura se vean obligados a prescindir siempre del apoyo de la Junta de Arbitrios en los asuntos que atañen directamente a la ciudad y en las que es precico hacer fuerza ante el Gobierno.

En septiembre de 1926 se efectúa en toda España un plebiscito convocado por Primo de Rivera. Este referéndum tuvo en Melilla escasísima repercusión, no alcanzando ni una participación de un 10 por ciento, frente al 80 por ciento de otras provincias. En Melilla, no se piensa que esta escasa participación sea debida a una repulsa a Primo de Rivera, sino que se achaca a la poca información y la mala planificación de las votaciones, de lo que se culpa a la Junta de Arbitrios.

Este acontecimiento da pie a un artículo del Telegrama del Rif, el 26 de septiembre, en el que se lamenta que Melilla sea tratada siempre como una ciudad de segunda categoría, por la costumbre de la ciudad de mantenerse al margen de los acontecimientos políticos españoles. Tras analizar que Melilla posee todos los organismos normales de cualquier otra ciudad española llega a la conclusión de que lo que hace a Melilla diferente es su régimen municipal, arcáico y poco operativo. El artículo termina señalando la necesidad de una reforma, ante "La excepcionalidad del régimen de Melilla".

Este proceso, que va a llevar a la creación de la Junta Municipal de Melilla, llega a su término en noviembre de 1926 , a pesar de que la Junta no será creada hasta febrero de 1927. Pero es en noviembre de 1926 cuando acaban definitivamente las incertidumbres, sobre si el Estatuto de Ceuta va a ser o no 
aplicado en Melilla.

El Comandante General recibe una Real Orden, en la que se le consulta sobre la conveniencia de aplicar el Estatuto en Melilla.

Que las pasadas experiencias habian enseñado prudencia a los melillenses, y que éstos tenían temor de volver a quedar fuera de las reformas, es una prueba la respuesta que las organizaciones económicas, excepto la Cámara de propiedad, dan al Comandante General al ser consultadas por éste.

Las distintas cámaras emiten un informe conjunto, en el que se contempla una serie de modificaciones posibles, y convenientes en el Estatuto, para aplicarlo en Melilla. Pero, sin duda, el recuerdo de lo sucedido en el año 21, motiva que se tenga buen cuidado en añadir que si estas reformas no son viables se acepta el Estatuto tal como está.

El Comandante General contestó al Gobierno, por tanto, que los melillenses apoyaban el Estatuto.

\section{0.-Creación de la Junta Municipal de Melilla}

La Junta Municipal de Melilla es definitivamente creada, tras varios meses de espera, el 20 de febrero de 1927, por Real Decreto. En el preámbulo, Primo de Rivera señala que al haber dotado a Ceuta de un Estatuto Municipal, resulta que las dos ciudades "tienen un régimen similar en sus principios básicos pero distinto en la estructura y organización". Ceuta posee un cuerpo legal actualizado, preciso y completo, mientras que el de Melilla es muy anticuado. Por esto se ha visto en la necesidad de uniformarlo, y a partir de ahora en Melilla regirá el mismo Estatuto que en Ceuta, aunque con algunas modificaciones, debidas al mayor número de habitantes de Melilla.

El Real Decreto da un plazo de quince días para la constitución de la Junta Municipal en Melilla, tras la publicación de este Real Decreto en la "Gaceta de Madrid".

El Estatuto que regirá en Melilla, cs por tanto, análogo al que se publicó para Ceuta, con solo algunas modificaciones, unas exclusivas para Melilla y otra generales para las dos ciudades.

Las reformas especificas para Melilla son:

- Pasa de 22 vocales ( 11 natos y 11 electivos) a 26 (13 de una clase y 13 de otra); entre los trece vocales natos cuatro, y no tres, serán vocales civiles.

En cuanto a las reformas generales:

- Se suprimen los recursos contencioso-administrativos a la Audiencia Provincial y se sustituyen por el recurso de alzada, ante la Presidencia del Gobierno. El 10 de marzo de 1927 se hacen públicos los nombramientos de los miembros de la Junta. Los cargos de presidente y vicepresidente son nombrados directamente por el Presidente del Gobierno. Estos cargos recaen en el general Calvo Lucia y en Cándido Lobera, respectivamentc. Esta clección es muy importante, por el preponderante papel que había tenido Cándido Lobera en la defensa de un Ayuntamiento 
civil, y por su significación e importancia en el ambiente cultural y político de la ciudad.

Entre los 17 vocales militares aparecen, como indica el Estatuto, jefes de cada cuerpo y armas representados en la ciudad.

Más interés tiene la composición de la parte civil de la Junta: Los vocales civiles son personajes muy representativos de la ciudad, estando representados los principales miembros de la distintas entidades, así, como las principales acividades económicas.

La Junta Municipal de Melilla está compuesta por: El Presidente de la Cámara Agrícola; Presidente de la Cámara de Comercio; Tesorero de la Cámara de Propiedad; Vicepresidente de la Cámara de Comercio; Secretario de la Cámara Agrícola; Presidente de la Unión Gremial Mercantil; Director del Banco de España; Director de la Compañia de las Minas del Rif; Presidente del Colegio de Médicos; Director del Banco de Bilbao; Director de la Compañia Minera "Setosalazar"; Director del Banco Internacional de Industria y Comerio; Representante de la Compañía Colonizadora; Presidente de la Comunidad israelita; cuatro comerciantes; un propietario, dos militares retirados; un periodista; dos maestros nacionales; un médico; un farmacéutico; un abogado y un obrero ebanista.

El 14 de marzo entró en funcionamiento la Junta Municipal, cesando simultáneamente la Junta de Arbitrios.

Aunque ya no es materia de este trabajo, que pretende ocuparse solamente del proceso de constitución de la Junta Municipal, es preciso hacer una breve mención de la labor y trayectoria de esta Junta. Por un Real Decreto de 31 de octubre de 1927, Cándido Lobera se convierte en Presidente de la Junta Municipal de Melilla.

La labor realizada por la Junta, se puede calificar de muy importante, pues tuvo que crear nuevas estructuras administrativas y reorganizar el presupuesto. La Junta Municipal tuvo una actuación excelente, de la que una parte importante del mérito corresponde a su presidente, Cándido Lobera.

Pero el mismo carácter preponderantemente civil había convertido a la Junta en un organismo extraño, que si no se convertía en un ayuntamiento era solo por una decisión personal de Primo de Rivera. Es normal, por tanto, que con Primo de Rivera caiga también la Junta Municipal. El 10 de abril de 1930 se crea un ayuntamiento en Melilla, pero permanecen en sus puestos los miembros de la Junta.

Es, finalmente, con la proclamación de la República, en 1931 cuando se consigue la meta tan esperada por un importante sector de la población melillense, igualándose el régimen municipal de Melilla al del resto de España. 